\title{
The Strength of "Grey Ties": A Case Study of Self-managed Community Centres for Elderly People in Tuscia District - Italy
}

\author{
Tony Urbani \\ Department of Disucom, Tuscia University, Italy \\ Received March 20, 2019; Revised August 23, 2019; Accepted August 30, 2019
}

Copyright $\mathrm{O} 2019$ by authors, all rights reserved. Authors agree that this article remains permanently open access under the terms of the Creative Commons Attribution License 4.0 International License

\begin{abstract}
The present work aims to overturn the common belief about elderly people as passive subject benefited by social welfare, showing an unedited vision of active and leading senior citizen in local communities. This qualitative-quantitative research is based on 393 cases divided in 21 social centres in Viterbo district in Italy demonstrate that social capital in specific environment is a flywheel for trust, health and happiness for senior citizen. This study shows that social capital could reduce daily hospitalization and medicines consumption for elderly. The community centres for elderly people managed by ANCeSCAO NGO are case of excellence, where remain critical issues, e.g. communication and conflicts, despite critical issues, they could be also a bridge for new welfare for seniors, an empowering and enabler social welfare, where bottom-up processes are balanced with top-down.
\end{abstract}

Keywords Social Capital, Health, Elderly People, Welfare, NGO, Happiness

\section{Introduction}

The aim of this research is to contribute in highlight the role of social capital for elderly people, in creating health and happiness. The present investigation focus on the aggregation points for elderly in Italy. The case study is an association named ANCeSCAO NGO, which is an acronym for: National Association social centres for the elderly and Community Gardens. The Association at the national level there are around 400.000 members distributed over almost the entire Italian territory, at province level members are about 13.000 (an over 65 to five is a member ANCeSCAO) distributed over the whole province of Viterbo. The ANCeSCAO manages social centres for the elderly through recreational activities, informative and educational activities ranging from playing cards and reading the newspaper, in excursions, information and health checks, language training and computer science, and more. Despite common sense that attributes a positive role to sociality in wide sense, it is not clear how social capital works to create or to sustain health and happiness for elderly. Moreover social capital is a wide concept, sometimes used by many authors in different ways. The present work would like to suggest limit and potential of social capital, elements that can be help or depress the positive impact of social capital.

\section{Materials and Methods}

The research is descriptive and exploratory it took the track with a background analysis, passing then to submission of semi-structured interviews with 11 Presidents of social centers for the elderly. We used the data from the semi-structured interviews to compile the questionnaires and explore areas that as searchers we had not thought. It is important to clarify this paper it is just a part of a greater research job that it took one year and half. The research group has visited 21 social centers sample, chosen for territorial distribution and Municipality above 5.000 inhabitants and below 5.000 inhabitants, in which they were submitted 393 questionnaires divided into 6 thematic areas (Identity, care, relations, services, health and happiness, customer satisfaction) and 242 questions. Data were processed with the SPSS software.

\section{Discussion}

\subsection{What is Social Capital?}

In the last three decades the concept of social capital 
(now SC) has become very famous in the social sciences, moving from sociological theory to everyday language. Some disciplines more than others took advantage of the concept for their analysis: Economics, education, sociology and public health (Ferlander, 2007). Despite popularity, SC does not embody a brand-new idea to sociologists. The insight that getting involved and participating in groups could have positive consequences for individuals and communities: "It is a basic knowledge" (Portes, 1998). In general terms, the SC is defined (Putnam, 1993) as a resource accessible through a social network, the central idea of the SC is that social networks have a recognizable value, the contacts influence the productivity of groups and individuals.

It turns out to be a relatively new concept in economy, although the literature on the subject is already rich in content as well as in disputes. You recognize the concept of SC the ability to capture important phenomena for economy, including trust and cooperation; accordingly, efficiency and economic growth (Pugno, Verme, 2012). To at the same time, economists argued that the concept of SC is vague in definition and a series of difficulties reside in its measurement. In recent years interest has grown, particularly among economists, about the SC-Welfare report individual self-perception and happiness. This link it would seem to be confirmed by a series of studies, but very dependent on indicators used for the detection of SC (Bjornskov, 2006, Helliwell, 2006, 2008, Ram, 2010, Leung et al., 2011).

Some surveys highlight how the relationship between $\mathrm{SC}$ and economic growth is substantially controversial, making emerge a not sufficiently positive role of the $\mathrm{SC}$ in the economic growth forecast (Olson, 1982), if not even of negative sense (Banfield, 1958), with the known definition of "amoral familism", which would characterize a dimension "distorted" social capital. The World Bank considers the SC a fundamental "tool" in order to reduce poverty, recognizing the character of good the public of voluntary organisations. Many interventions by the World Bank are aimed at the formation of voluntary organisations, to which the collective management of services is delegated public, micro-credit and entrepreneurship (Sabatini, 2004). In World Bank's intentions, strengthening participation in the arising from the above-written initiatives should contribute to the dissemination of trust and information, ultimately stimulating development processes. This kind of interventions it is effective in institutionally weak contexts, where the state and the market fail to ensure a decent social protection. This guidance could lead to the belief that it is possible to addressing the problems of poverty and inequalities by scaling further public intervention and making exclusive reliance on civil society (Sabatini, 2004), guidance that the writer does not share at all.

A turning point of research on social centres for elderly people in Tuscia (Tuscia is the alternative name of Viterbo district in Lazio region-Italy) is to underline how the State or institutional bodies, at every hierarchical and spatial level, alone are not enough and cannot be enough even the only market or the private social sector to ensure the development and well-being of a community, the case presented here stimulates you to think about a sustainable and empowering welfare for the users, and therefore know out of the shoals of a mere welfarism to return citizens power in management, effectiveness in results, empowerment individual and collective.

The data in this study refer us to a framework in which only through the optimum operation of all the elements is effective, efficient and sustainable welfare. The public administration should support the realities of social centres for elderly, guaranteeing their independence and autonomy, moreover in the market social centres can acquire products and services and in turn propose some services that the PA and the market do not manage to secure.

The definition of the World Bank's SC: "Refers institutions, reports and standards that form the quality and amount of social interactions of a society. Growing trials demonstrate that social cohesion is fundamental to prosperity of the companies and their sustainable development. Social capital is not only the sum of the institutions that support a society, is the glue that holds them together". The glue holding them together, a tone perhaps a little too apologetic, but confirming the previous lines, the idea that sustainability social and economic steps for the SC, but at the same time a vision little circumstantiate of the same SC, especially in the elements thinners and hindering it.

So, clearly and unequivocally define the SC appears as a task for nothing simple. The concept is inherently multi-dimensional, and it would therefore be more correct to speak of capitals rather than an indistinct monad, taking consider which types of SC facilitate certain processes social, economic, cultural, civil.

One of the first mistakes not to be committed, in the analysis of effects is considering the $\mathrm{SC}$ as a panacea. Along the literature on the subject, we can repeatedly incur the assessment critical of case studies, in which some types of SC are far from desirable, not only, even an excessive presence could be undesirable. There is a lack in the debate on the SC of reflections that relate to the quality and quantity of SC in different socio-economic, political and cultural contexts (Trigilia, 1999).

Putnam (2000) recognizes how SC can imply negative or positive externalities and proposes the famous distinction between bonding and bridging SC in order to understand the different effects. When cooperation and trust (for Putnam synonymous with SC) are relegated within the groups, in this case, the externalities mistrust, distrust and opportunistic attitudes, could be directed outside the group. The most classic example is the family, but it can also cover an association, a circle of people, a trade union or a party. 
Does not convince the idea that a strong bond within the family or a restricted circle can bring negative externalities to the community, even in this case it seems to be a deficit the analysis of the territorial and cultural context, which therefore considers analytically equal a family of a capital of northern Europe, for example, with a family of a rural area of southern Europe.

The second type of SC bridge emerges when new links between groups, trust and cooperation arise would be increased. The example in this case it could be a voluntary association that increases the ties with other associations and with the fabric of the community. In addition, you might consider the levels of formality/informality of the bonds and directions thereof, or the strength/weakness of the bonds; Coleman (1988) emphasized the importance of horizontal ties and "the strength of weak ties".

Recent researches would confirm that cs bonding and SC bridging can be considered as two distinct variables, and that the last form would contribute to economic growth, on the other hand, the former would obstruct it (Knudsen et al., 2010; Beugelsdijk and Smulders, 2009). An interesting point of view, that emerges from the reading of a series of studies look at the two bonding and bridging variables, as two sides of the same latent variable, rather than two distinct variables, this would imply that they could not be conceived as different dimensions of the SC but, in fact, two opposite sides of a single dimension which could probably contain other dimensions (Pugno, Verme, 2012).

Another "error" to avoid is exchanging the SC with the social networks. Although it is often referred to as the network of relationships that individual and collective subjects, this definition risks to be too static. It could be more useful to refer to the product of social networks, so the relationships within the networks and between networks, which from time to time can be trusted, cooperation, or closure to non-members of the group of reference the product itself of the interactions can also be the glue for the creation of new social networks.

We cannot neglect eminently relational nature of the concept at micro level as an attribute of individuals, meso as a feature of organizations or macros by intending a social structure at a broader level (Andreotti, 2009). As previously mentioned, the multidimensionality is inherent in the concept, whose fields of application and relationship are multiple, the SC can be put in relation to other elements such as: local development, health, democracy, welfare state, education and human capital.

In the last thirty years we have witnessed the success of this heuristic instrument; the multidimensionality and trans-disciplinarily had certainly facilitated the diffusion: we must emphasize that even the vagueness has often accompanied her to success.

To some extent the society of the network and networks merges into the concept of SC, from it bridging the various disciplines scientific, in our specific case it can be said that: sociology, economics, medicine and psychology found themselves together in this research work and therefore fully covered in the analysis in relation to the $\mathrm{SC}$.

Analysing the luck of the concept of SC would be a long-term work with uncertain results.

There is who look at social networks, human relationships and their product as in danger and impoverishment, this is the approach of Putnam (Putnam, 1995), on the other side there are those who insist on role of SC as a fluidizing of the company's distortions of market (Fukuyama, 1995). Fukuyama is inside this approach, by enhancing the role of trust: networks that generate trust and that can lower transaction costs, for example, the handshake to seal a commercial contract in place of a document countersigned by the parties provides for onerous safeguards to protect contractors.

Coleman defines SC through its functions, not a single entity, but a variety of different entities, with two elements in common: they all consist of some aspects of social structure, and facilitate certain actions of the actors, whether they are individual or collective actors. Like other forms of capital, the SC is generative and makes it possible to achieve some ends in the absence of which it would be impossible to get those results. Like the physical capital and human capital, the SC is not completely fungible. A given form of valuable SC in facilitating some processes, could be useless, even detrimental to the attainment of other objectives (Coleman, 1988).

The concept of SC has been developed relatively late, the first official definition appears in 1916 by the school director Lida Judson Hanifan, who placed emphasis on intangible assets such as solidarity and goodwill, which they would be the most valuable resources a community possesses.

French sociologist Pierre Bourdieu describes SC as the set of current or potential resources linked to a stable network, institutionalized (Bourdieu, 1980). Bourdieu believes that $\mathrm{SC}$ is micro founded and it is an individual resource that explains together cultural, economic and symbolic capital to reproduce the social classes. Explicating: The relationships that I cultivate and entertain with the members of my own social class create the prerequisites for class reproduction.

$\mathrm{SC}$ is seen from time to time both as a collective asset and as a private good, in fact it is both, so it is only the perspective of analysis that from time to time moves the focus, higher individual or collective aspects, retracing dualisms that are still in modern sociology, but that should find moments of synthesis and unity in favour of knowledge perhaps more uncertain, but richer and more complex.

This Research work on elderly in the province of Viterbo belonging to the ANCeSCAO association has valued both the aspects of social capital, both as a public good both as an individual asset.

Moving a step back in history and sociology literature, we can say that the concept has remained background in all 
classical sociology from Durkheim to

Weber up to Simmel. The social order for Durkheim is guaranteed from adherence to social rules; in his essay on the Division of Labour in Society, he highlights how the contractual relations imply the development of rules that regulate the contract. The moral basis of these norms in modern societies is guaranteed for Durkheim from the Division of labour that gives rise to "organic solidarity", which is opposed to "mechanical solidarity" distinctive of pre-industrial societies. SC in Durkheim it is the adherence to norms and values that are the basis of the "macro-founded" model of the SC, which sees it as a collective good rather than the individual.

In Weber we can trace SC in "The Protestant Sects and the Spirit of Capitalism" (Trigilia, 1999). Weber's approach concerns both the $\mathrm{SC}$ as well that brings benefits to individuals belonging to an organization, both as a collective good, with aspects and implications negative and positive on society as a whole. Simmel being one of the fathers of Social Network Analysis (tool very popular for the measurement of SC), contributes to the analysis on the $\mathrm{SC}$ with the theory of the functioning of the dyads and the triads (Chiesi, 2000). Individuals are for Simmel included in different social networks, interweaving and entering into interrelation between they make up behaviours and convictions.

The benefits of SC, as previously declared, can address both individuals and communities in a wider sense, the socio-economic literature focused on link that binds "success" and therefore the possibility of finding a job and career and a given amount of SC.

In recent years there has been an increasingly marked attention to the relationships between SC and happiness, $\mathrm{SC}$ and health. It can be noted how the individual increase of happiness, and health, it is also a collective good as well as private. the case in which the conquest is different is instead different of a job by a larger network does not appear necessarily as good for the community, but sometimes the its exact opposite, favouring individuals with larger networks, rather than impeccable professional preparation.

The case of the Italian labour market is in some respects emblematic: networks play a key role, guaranteeing in considerable measure of access to the labour market (Reyneri, 2011), rather than bodies responsible for these purposes (employment agencies). In Italy there is a strong orientation towards the "clan" and then the co-optation falls within these canons; taking an act of this peculiar characteristic of the Italian labour market, one might think of labour policies that approach workers and entrepreneurs and make them familiar.

In a context characterized by strong corruption, some equipment of $\mathrm{SC}$ could exacerbate the problem rather than find it a solution or clear the effects. The SC can generate health and, as we will see in the following pages, this research shows that it is possible the hypothesis that the improvement of the conditions of health in the communities generate a reduction in public spending.

There is a paradox that I would like to underline, if the $\mathrm{SC}$, that dates conditions contribute to the improvement of health and therefore reduction of public spending is desirable in a system political-economic that "sanctifies" the GDP and growth tout court. It could be argued that by reducing health expenditure, it could be better addressed on other expenditure items socio-educational, but the effect of reducing the GDP would be felt and, trivially, public health at reduced costs would not be desirable in a framework that sees the GDP as indicator of well-being.

We have said of the SC as a property of the individual and as a private good, likewise it can be analysed through its collective properties and as a characteristic of an aggregate spatial and social in a wider sense. The analysis has taken vision and analysed both perspectives, noting for example the degree of participation and trust within the ANCeSCAO network of the province of Viterbo. It is good to emphasize that there is no single way of knowing even one type particular SC, but there are many approaches, some of which they have been more tested than others.

Robert Putnam, probably the most famous sociologist for the studies on SC, has a perspective linked to the definition of the concept as a collective property; the scholar, in fact, tries to explain the performance of Italian regions through one lower or higher endowment of SC, translatable, in this case specific, such as trust, participation and associationism.

The analytical theoretical framework on which Putnam moves can tell us very much of our investigation; in the classic book: The civic tradition in the Italian regions (Putnam, 1993), the problem posed is inherent to the effectiveness and efficiency of public institutions, in the case in question the Italian regions, and the answer that the author proposes is based on the presence or absence of cs. The definition of cs is similar to generalized trust (it also exists a specific trust that is relative to the network to which it belongs).

In the research on the old social centres of Tuscia we have held together the micro founded vision of the SC, as well as the individual, and the macro founded vision, as well of a community.

We have analysed the relationships that bind SC and health, with results that have highlighted levels of drug use and hospitalization considerably lower than the reference sample (Fondazione Turati, 2013), with possible health cost savings that could to ensure a better allocation of socio-health resources.

The relationship between SC and trust appears as one of the objects more studied especially in economics; trust would create the conditions to bring down the transitional costs and would facilitate the exchanges. There are at least two types of trust, the specific or focused on a group and the generalized one that is beyond a reference group, be it the family or an association to volunteer. However even in 
our sample the specific trust is greater than the generalized one, this element does not prevent extremely positive actions of solidarity addressed to the local community or distant communities spatially from its own. There is a further type of confidence analysed in the social sciences, is the so-called institutional trust, which tends to verify the degree of positive expectations on institutions such as government, police, political parties, unions and other public entities in a broad sense.

A strong network of friends and having a good number of them seems to be correlated with higher levels of happiness. Also having a good family network and spending time with loved ones is tied to higher levels of happiness (Leung, Kier, Fung, Fung, Sproule, 2010). Overall, having good relationships is an element fundamental to happiness, more than material factors. In this case you confirm the thesis of Coleman (1988) and Putnam (2000) on the importance of social ties.

\subsection{The Social Capital of Elderly in Italy}

Among the 28 members of the European Union, currently there are 4 people in working age for every ultra-65-year-old.

Eurostat estimates show that trends in the demographic and migratory will vary this relationship, up to reaching a halved value in 2060: 2 people in working age for each over 65. This figure will not affect the National (and European) welfare policies, which is required to pursue appropriate structural reforms in order to ensure the financial sustainability of their systems in the long run.

The spokesperson for the European Commission declared that "the aging of the population is one of the challenges that Europe has to face, together with the climate change and globalisation".

The world of the elderly is often observed for the budget implications in the area of welfare and pensions. This vision, although partial, undoubtedly has license to exist, and some data on aging generate more than a lawful concern, but if the world of the third age is relegated to this analytical cut, we can object as this viewpoint is near-sighted; focused only to criticalities and not to the social, cultural and economic value made by the elders.

So, what does it represent in general terms the SC of Italian senior citizens and what socio-economic impact of unpaid activities that Italian elders carry out? To those questions attempts to answer two research by Ires (Institute for Economic and Social Research - welfare and rights Area of citizenship).

The perspective starting point is the improvement of the health and living conditions of the elderly population, which has generated political and cultural orientations to believe that older people should increase their contribution to the economic and social well-being, both by participating more in life, either by accepting to contribute in activities of social and cultural interest (Ires, De Sario,
Sabbatini, Mirabile, 2010). The investigations try to demonstrate how the contribution of elderly people to the social and economic life of the country is far from irrelevant, for the help that grandparents bring to families for both voluntary and collective interest activities in which the senior citizens are involved.

It is necessary to look at the aging problem and the potentials that self-organized associations could provide, supported by the institutions. Holding together more elements trying to understand how they interact each other: $\mathrm{SC}$ on health, but also a good health on SC, happiness on $\mathrm{SC}, \mathrm{SC}$ on civic commitment and the participation. SC has a positive role on the health of the elderly of social centres and equally on their happiness. The SC is a necessary condition (but not the only one) for a sustainable welfare.

Ires estimates that between the informal aid activity, support for family loads (helping minors for example) and commitment in voluntary organizations, the value expressed in monetary terms is about 18.3 billion euro every year, equal to $1.2 \%$ of Italy GDP (Ires, De Sario, Sabbatini, Mirabile, 2010).

Another data on which Ires researchers focus is the possibility of generating positive external economies, in particular for women and their employability, therefore, the contribution of the elderly is not limited and does not end at the intrinsic value of the activity, but it is also able to generate economic and democratic processes which go beyond calculation of monetary value of their contribution. Ires declares that free support grandparents could support the occupation of 800 thousand Italian women, who in merely arithmetic terms bring $2.4 \%$ of the Italian GDP External economies generated by the activities of the elderly are not limited only to those activated in the circuits of social production, family relationships between different generations, parenting, proximity relations, but they are linked together fundamentally to the social services economy systems. Unpaid work, in fact, is an important node of the contribution of citizens to a relational economy, of which the participation of users and citizens does not represent only an index of democracy and involvement, but also of productivity and economic efficiency in the broader sense (Ires, De Sario, Sabbatini, Mirabile, 2010, p. 6).

If SC is important for the purpose of holding a democratic, participatory, efficient and responsible social fabric, the loss of SC would therefore have catastrophic effects, not just for the purpose of sustainable welfare, but in the relation to society as a whole.

Some evidences refer us to a framework which is under-stretched and little analysed: seniors are at high risk of loss of SC and loneliness for many factors including chronic diseases, mobility difficulties, loss of family and friends. The Italian welfare has never set the maintenance and implementation of the $\mathrm{SC}$ as a clear objective, not only for elderly people, but for all citizens. In the light of what we have analysed so far, it should be among the primary objectives of Italian welfare to maintain and upgrade the 
SC, not for manipulative optics, but facilitating pathways that lead to the strengthening of human relations, so as to ensure economies of scale, purpose and knowledge.

\section{Results}

\subsection{The Social Capital of ANCeSCAO Viterbo and Health}

The issue of individual health related to social capital is frequently associated with social inequalities and consequent health inequalities. ANCeSCAO network provides to a rebalancing of social, and individual health chances. Poor health levels are generally associated with the scientific literature at low schooling, one of the ANCeSCAO effects is to act as a social compensator, economic and health returning, social occasions and empowerment.

At least three mechanisms have been identified to have a positive role in the relationship between $\mathrm{SC}$ and individual health (Rocco, Suhrcke, 2012).

The first concerns: improving access to information relevant to health. Having a very extensive social network and activate it frequently through contacts with friends, relatives, participating in social events or being members of an association helps to have more information about how to prevent or cure diseases, and what the best remedies, hospitals and medical specialists are. Improving access to information is particularly important in the field where information flow between "health providers" and "consumers" represents a market failure in a very pervasive way.

In the sample ANCeSCAO only $15 \%$ of respondents perceive to spend the day alone, relative majority of respondents $36 \%$ claims to invest their time predominantly with family members, $30 \%$ perceive the flow of daily time mainly in the senior social centres. In senior social centres there are targeted socio-health initiatives, health information, pressure measurement, blood sampling, glycemic measurements and light gymnastics for seniors.

The social capital is understood as access to "informal health care" in case of illness or need. The support of family, friends or volunteers for personal care is a relevant fact both by a social and economic point of view. Moreover, the support that older people guarantee families and communities generally free human and financial resources that contribute to local and national development. Even in "developed" countries, where health care is structured and rooted on territory, there is a strong request for informal care; not underestimate the fact that the assistance of a friend or family member has an emotional bearing superior to "institutional" care. A report (Yandle \& Buckner, 2017) evaluates the cost of informal treatment in the UK at around $£ 87$ billion, roughly the same budget as the British national health service.
In undeveloped countries, the informal care system is much more extensive than in the so-called developed countries, where the formal system is more structured of personal care. For a critique of the concept of development refer to the book: "I giovani e il mondo che cambia, dallo sviluppo alla decrescita" (Bisogni, Piana, Urbani, 2011).

Support and mutual assistance of informal and formal systems is only possible in a climate of trust. Trust can be developed through continuous interaction. Informal care can also be understood through the famous "Prisoner's Dilemma", a classic of the literature of game theory. In the prisoner's dilemma two people that would benefit from collaboration, do not cooperate in practice or in the simulation because they do not trust each other. It has already been said that trust is a possible product of the network interactions, here we reiterate that a welfare in support and development of the SC is desirable under many points of view, not least the possibility of a real balance between the formal and informal care systems.

Let us look at a comparison between the reception of aid and aid performance within the sample ANCeSCAO. The questions included a maximum of three answers, receiving help is maximum by cohabiting family members (generally the spouse), $55.2 \%$, then follow the non-cohabiting relatives to $43.8 \%$, and friends and neighbours at home with $26.2 \%$, only a $5.3 \%$ is specific to the members of the social centres. If we cross the data, $58.5 \%$ declare that they have met their friends at the senior social centres, given in a more relevant question: where do they meet friends? 74.3\% meet them at the social centres. The ANCeSCAO network is an extraordinary distributor of informal care.

Being part of an elderly social centre ensures access to a care network and mutual help, this data was also detected through informal talks with members. A piece of information that does not emerge from the questionnaire is the care that is provided during a hospitalization; there is a strong stimulus towards the sick to return as soon as possible to the centre and not to let go down; psychological-affective support is a tremendous value in the care of the sufferer, as evidenced in multiple studies.

Well-organized groups are more effective in lobbying. The SC can also serve to coordinate the efforts of people in lobbying in comparisons with public authorities. Through its network, ANCeSCAO manages to attract doctors and professionals of health who carry out free consultancy activities and prevention, also the relationship with local associations, for example the Italian Red Cross, the Knights of Malta, is alive and profitable. The SC of ANCeSCAO in favour of lobbying actions is a reality that is expressed in many rivulets, also justified from very respectable numbers, about 13,000 registered in the territory of the province of Viterbo on a population of 317,000 inhabitants.

Trust and participation in civil, social and politics engagement plays a fundamental role in psychological health. Participation in political parties would be a negative 
element for individual happiness, on the contrary, participation in voluntary associations is positively associated with factors of happiness and self-esteem.

According to the World Health Organization, mental illnesses were the cause of $13.1 \%$ of all diseases in 2004; with the unipolar depression, which by 2030 will be the main cause of disability worldwide, this already high percentage is destined to increase (WHO, 2002).

Individuals who perceive high levels of trust and reciprocity in their communities have better health, due to the reduced exposure to factors such as chronic stress (Giordano \& Lindström, 2010; Wilkinson, 1996). Confidence levels together with regular exercise also affect psychological health, on the contrary high levels of crime and chronic stress are known elements of a deterioration of psychological well-being (Aneshensel \& Sucoff, 1996).

Seniors interviewed who claim to have been quite healthy in the last year are $66 \%$, very good $13 \%$, added together in a hypothetical area of good health amounted to $79 \%$; the area of bad health in the last year amounts to $21 \%$.

To the question: Do you participate regularly in outdoor activities which involve a certain physical effort? 73.5\% answer affirmatively, the remaining $26.5 \%$ respond negatively; the data is partially overlapping and consistent with the one previously analysed.

The consumption of drugs: $84 \%$ of the sample consume drugs regularly, the specific data of the type of drug has not been investigated, but being a regular consumption, it is possible to assume that they are drugs for the most part of A-band. The "A-band drugs" are used in the treatment of chronic diseases and acute and being considered essential for ensure the care provided by the essential levels of health care they are charged to the national health system.

During my bibliographic research I came across a very interesting book, a research funded by the Turati Foundation in Italy. The text: "Between fears and hopes The condition of the elderly in Tuscany, Lazio and Puglia regions", contains interesting insights on the condition of the elderly, distinguishing between the elderly caretakers and caregivers.

Within this study it was possible to cross two questions about the health of the elderly. The result and its interpretation remain problematic as the crossover of the data was made between the sample ANCeSCAO and the sample relating to the three regions - Lazio, Puglia and Tuscany - where there is a certain variability.

The intersection of data brings out what we have called ANCeSCAO effect. Both in the consumption of drugs, and in the days of hospitalization we can observe a positive effect in the ANCeSCAO sample, which is particularly evident in the age groups 61-65 and 66-70, in the subsequent bands the effect persists, but tends to decrease: the ANCeSCAO sample results in less medication and less hospital days. The savings in health care although evident is difficult to quantify financially, but if confirmed by one's successive research it would be an impressive figure, which would justify the beyond all doubt, massive investments in networks with a strong vocation social-health, of which ANCeSCAO is a good example that stands out for the efficiency and effectiveness of the organization. How would you explain this given? Access to better information could influence towards more responsible and aware consumption of drugs, reducing them to the strictest necessity: information on conscious use of the drugs are recurring activities of the Association. Moreover, prevention and therefore keeping in "good health", and doing suitable sport activities would positively affect the reduction of drug consumption. Both processes take place through the access of the associative network.

There are also many informal elements to support the data. During the interviews we found that the support network of members, is responsible for visiting those who go to the hospital, stimulating a speedy recovery and the prompt return to the centres, to continuing one's life and activities together with other members: the aspects of informal care are determinants of individual health.

\section{Conclusions}

Research on the elderly social centers of the province of Viterbo affiliated to the ANCeSCAO association has given considerable guidance and empirical evidence to reflect on.

Participants in the activities and life of social centers tend to be in good health, obviously the data require further study, but the indication is relevant: reduced drug consumption, lower hospitalization. If the data were confirmed in further studies, the economic impact could be assessed by quantifying the savings in public spending, but it can already be said that this saving, although not quantified, would seem to exist.

The relationship between social capital and health has contributed to explaining a considerable part of the well-being and health of the participants in the activities of the centers, the elderly who participate in networks such as the ANCeSCAO benefit from some advantages: better access to information relevant to health, access to an informal health care network, effective lobbying activity. Beyond these generic advantages, related to belonging to a structured network, the activities of the centers are strongly directed towards the promotion and maintenance of health, for example: through courses of soft gymnastics, meetings with doctors and health and social specialists, prevention days.

We must think of the elderly as active and not passive subjects of welfare, the elderly people are not only a cost, but a great resource, often underestimated, undervalued and debased. A truly effective and efficient welfare must set the goal of citizen empowerment, it must expand the spaces of possibility and freedom. To do this, we must be able to listen to the real needs of citizens and organize services that respond to real demands, but at the same time 
are not closed boxes. A welfare system that can be improved and implemented by citizens, in which economies of scale, scope and knowledge can be achieved. A non-obvious path that requires a high level of organization, continuous monitoring of results and critical issues, the key factor is the involvement of the actors, not from a rhetorical or formal point of view, but at the level of operational practices, as well as projects, possible only in a system of mutual trust).

There is a need to rethink social actors as capable of creating value, innovative ideas and paths and not only as users of public spending or as subjects able to spend efficiently; the financial issue is a very significant problem, but it must be accompanied by reflections on the quality of resource allocation.

The survey carried out underlines that it is necessary to invest in social networks that make possible, in addition to substantial savings in public spending, better quality services for citizens, making users of the service accountable through a participatory and democratic perspective. The Italian case shows the need to reorganize public spending more in favour of networks than direct transfers, having clear and shared indicators.

\section{REFERENCES}

[1] Pugno M., Verme P. (2012), Life Satisfaction, Social Capital and the Bonding-Bridging Nexus. Policy Research Working Papers.

[2] Bjornskov C., (2006), The multiple facets of social capital in European Journal of Political Economy.

[3] Ram R., (2010), Social Capital and Happiness: Additional Cross-Country Evidence in Journal of Happiness Studies.

[4] Andreotti A., (2009), Che cosa è il capitale sociale, Carocci, Roma.

[5] Olson M., (2002), The varieties of eurosclerosis: the rise and decline of nations since 1982 in Economic growth in Europe since, 1945.

[6] Banfield E.C., (1958), The moral basis of backward society, Free Press, Glencoe.

[7] Knudsen T., (2010) Darwin's Conjecture: The Search for General Principles of Social and Economic Evolution.

[8] Beugelsdijk, S. and Smulders, J. (Sjak) A., (2009) Bonding and Bridging Social Capital and Economic Growth in CentER Discussion Paper Series No. 2009-27.

[9] Fukuyama F., (1995) Trust: The social virtues and the creation of prosperity, New York: Free Press Paperbacks.

[10] Chiesi A.M. (2004) Social Cohesion and Related Concepts. In: Genov N. (eds) Advances in Sociological Knowledge.

[11] Bisogni M.M., Piana V., Urbani T. (2011), I giovani e il mondo che cambia, Anicia, Roma.
[12] Bourdieu, B. (1980), Le capital social, Actes de la récherche en sciences sociales, vol. 31, gennaio 1980, pp. 2-3. Bravo G., Sociologia economica, La crisi del welfare state.

[13] Leung A., Kier C., Fung T., Fung L., Sproule R. (2013) Searching for Happiness: The Importance of Social Capital. In: Delle Fave A. (eds) The Exploration of Happiness. Happiness Studies Book Series. Springer, Dordrecht

[14] Coleman J.S. (1988), Social Capital in the Creation of Human Capital, in «American Journal of Sociology», Vol. 94.

[15] Yeandle, S., \& Buckner, L. (2017). Older Workers and Care-Giving in England: the Policy Context for Older Workers' Employment Patterns. Journal of cross-cultural gerontology.

[16] Giordano, G., Lindstrom, M., (2010), The impact of changes in different aspects of social capital and material conditions on self-rated health over time: A longitudinal cohort study in Social Science \& Medicine.

[17] Aneshensel, C., \& Sucoff, C. (1996). The Neighborhood Context of Adolescent Mental Health. Journal of Health and Social Behavior.

[18] Wilkinson, R. (1996) Unequal Societies. The Affliction of Inequality. London: Routledge.

[19] European Commission (2014), Employment and Social Developments in Europe (ESDE) Review.

[20] Eurostat (2013), European Social Statistics.

[21] Ferlander S. (2007), The importance of different forms of social capital for health, in «Acta sociolgica», 50, 2, pp. 115-128.

[22] Fondazione Turati (2013), Tra paura e speranze. La condizione degli anziani in Toscana, Lazio e Puglia, a cura di Roberto Gambassi, Lucia Pugliese, Il Pozzo di Micene, Firenze.

[23] Giordano G.N., Lindstrom M. (2011), Social capital and change in psychological health over time, in «Social Science \& Medicine», 72, pp. 1219-1227.

[24] Helliwell F.J., Wang S. (2010), Trust and Well-Being. Ifll (2009), Thematic Paper.

[25] Ires, Mirabile M.L., De Sario B., Sabbatini A. (2010), Il capitale sociale deglianziani. Stime sul valore dell'attività non retribuita, Ires.

[26] Leung A., Kier C., Fung T., Fung L., Sproule R. (2011), Searching for Happiness: The Importance of Social Capital, in «J Happiness Stud», 12, 1, pp. 443-462.

[27] Portes A. (1998), Social Capital: its Origins and Application in Modern Sociology, in «Annu. Rev. Sociol.».

[28] Putnam R.D. (1995), Bowling Alone: America's Declining Social Capital, in «Journal of Democracy», January 1995, pp. 65-78.

[29] Putnam R.D. (1993), La tradizione civica nelle regioni italiane, Mondadori, Milano.

[30] Reyneri E. (2011), Sociologia del Mercato del Lavoro, il Mulino, Bologna. 
[31] Rocco L., Suhrcke M. (2012), Is social capital good for health? A European perspective, WHO Regional Office for Europe, Copenhagen.

[32] Sabatini F. (2004), Il concetto di capitale sociale nelle scienze sociali, in «Studi e Note di Economia», 2, pp. 73-105.

[33] Trigilia C. (1999), Capitale sociale e sviluppo locale, in «Stato e Mercato», 57.

[34] World Health Organization (2004), The World Health. Report 2002. Reducing Risks, Promoting Healthy Life. 